\title{
El rol de género como fundamento humanista de la formación para la ciudadanía'
}

\author{
Wilmer Hernando Silva Carreño ${ }^{2}$ \\ Jorge Hernán Beltrán Martin ${ }^{3}$
}

\begin{abstract}
Resumen
Objetivo. Analizar desde una mirada crítica la comprensión social que tiene el ámbito educativo respecto al género. Se presentan algunas perspectivas de comprensión humanista y el alcance político de esta categoría constitutiva de lo humano.
\end{abstract}

Método. Ejercicio etnográfico y análisis crítico desde el enfoque humanista de las capacidades desarrollado por Martha Nussbaum.

Resultados. El genero constituye un elemento fundante de la identidad de la personal, no sólo de algunos grupos minoritarios sino de la sociedad en general, lo cual configura su alcance político en la constitución de la ciudadanía incluyente.

Palabras clave: Rol de género, inclusión, desarrollo humano, educación.

1. Artículo producto del proyecto de investigación "Ciudadanía y género: fundamentación teórica para la formación humanista desde el enfoque de las capacidades de Martha C. Nussbaum", Universidad de San Buenaventura, Bogotá, 2015.

2. Licenciado en Filosofía y Magíster en Ciencias de la Educación, Universidad de San Buenaventura, Bogotá; Doctor (c) en Educación, Universidad Pedagógica Nacional. Docente Universidad de San Buenaventura, Bogotá; Docente Secretaría de Educación Distrital, Bogotá.

Correo: swsilva@usbbog.edu.co

3. Licenciado en Filosofía y Teología; Estudiante de la Maestría en Ciencias de la Educación, Universidad de San Buenaventura, Bogotá; Docente Secretaría de Educación Distrital, Bogotá.

Correo: jorgehbeltranm@yahoo.es 


\title{
The gender role as a humanist foundation for citizenship
}

\begin{abstract}
Objective. Analyze from a critical perspective the social understanding that has the education system regarding gender. Some perspectives of humanistic understanding and political significance of this constitutive human category are presented.

Method. Ethnographic exercise and critical analysis from the humanist approach of the capabilities developed by Martha Nussbaum.

Results. The genre is a fundamental element of personal identity, not only in some minority but in society in general, which sets its political significance in the constitution of inclusive citizenship.
\end{abstract}

Keywords: Role of gender, inclusion, human development, education.

"La escuela puede enseñar contenidos reales y concretos sobre otros grupos raciales, religiosos y sexuales o sobre las personas con capacidades diferentes [...] puede fomentar el sentido de la responsabilidad individual [...] Puede promover el sentido crítico [...]" (Nussbaum, 2010, pp. 73-74).

\section{Introducción}

El mundo globalizado genera temores con respecto al ser humano, en la medida en que se le desvirtúa, se le cosifica desde una perspectiva utilitarista y se desconoce su valor y la riqueza de su humanidad; sin embargo, también genera esperanzas, dado que, como mundo global, deviene bajo la configuración de un mundo multicultural que rompe las fronteras, visibiliza la diversidad cultural, establece o reivindica nuevas formas de pensar, de sentir y de manifestar la identidad del ser humano. 
En este sentido, emerge el reto de no permitir la invisibilización de una forma particular de expresión de dicha multiculturalidad dada a través del reclamo de los derechos y el respeto a la diferencia de los grupos minoritarios. Este artículo pone en discusión el sentido humanista y político que implica centrar la atención en aquellas formas diversas de expresión de la sexualidad humana, esto es, aquellos grupos minoritarios que luchan por tener un espacio en la sociedad, especialmente, desde el ordenamiento jurídico que les permita el despliegue de su identidad y la praxis de sus derechos, especialmente, la igualdad y la inclusión. Así, se asume el género como categoría central de análisis en tanto permitirá dar cuenta de una mirada crítica y reflexiva de diversas pre-comprensiones conceptuales que se presentan en el ámbito educativo con relación a esta categoría.

Para ello, en el marco de la investigación base desarrollada de este artículo, se recurre al enfoque humanista de las capacidades de la filósofa norteamericana Martha C. Nussbaum para fundamentar el carácter y el sentido humanista con el que se aborda el tema planteado y se referencia un trabajo de campo que permite mostrar dichas precomprensiones, con el fin de establecer algunas perspectivas críticas del género como elemento fundante de la diversidad humana, en tanto conlleva la consideración de que lo fundamental es la persona como ser vivencial en el contexto actual de la sociedad, por demás, globalizada.

\section{Descripción del enfoque humanista de las capacidades de Martha Nussbaum}

Martha Nussbaum desarrolla el enfoque de las capacidades pertinentes al ser humano, en la búsqueda de la promoción de la persona, en el marco de la reivindicación de la dignidad y de la plenitud de los derechos humanos, tanto personales como en relación con el otro, para lo cual articula la educación como campo fundamental de la sociedad, las políticas estatales y su relación y constitución desde la equidad y la justicia social. Este enfoque lleva a considerar el humanismo en el mundo contemporáneo es un reto que reclama hacerlo manifiesto, especialmente desde una racionalidad crítica que lleve al redescubrimiento del sentir de lo humano, de la persona concreta que no quiere ser reconocida como un elemento del capitalismo, del mercantilismo, sino, llanamente, como ser humano, que siente, que sufre, que tiene algo que decir y hacer en el contexto en que se encuentra.

En el marco de este enfoque, se considera que el rol de género implica la resignificación de lo humano, debido a la inmersión en los cambios rápidos que el mundo globalizado presenta y que no ha dado espacio para atender al ser humano desde su realidad misma, se han establecido imaginarios del capitalismo, del uso del otro para el beneficio personal, y en contadas ocasiones se piensa en su promoción. A esto confluyen las políticas públicas: “Los dirigentes de los países 
suelen centrarse exclusivamente en el crecimiento económico nacional, pero sus ciudadanos y ciudadanas se afanan, mientras tanto, por conseguir algo distinto: unas vidas significativas para sí mismos” (Nussbaum, 2012, p. 37).

Martha Nussbaum aborda la concepción de lo humano, como una crítica a la política y a la comprensión del desarrollo de una sociedad, en cuanto reclama una vuelta a una subjetividad dialógica, esto es, la expresa relación de encuentro y reconocimiento del ser personal a partir del acercamiento con el otro, expresamente, a través de la imaginación o la posibilidad de ponerse en el lugar del otro, más allá del el utilitarismo y la manipulación. En este sentido indica:

Vamos detrás de las posesiones que nos protegen, nos satisfacen y nos consuelan: aquello que Tagore describe como el "disfraz exterior" de lo material. Sin embargo, parecemos olvidarnos del alma [...] Parece que olvidamos lo que significa acercarnos al otro como a un alma, más que como un instrumento utilitario o un obstáculo para nuestros propios planes.

[...] me refiero a las facultades del pensamiento y la imaginación, que nos hace humanos y que funda nuestras relaciones como relaciones humanas complejas en lugar de meros vínculos de manipulación y utilización [...] (Nussbaum, 2010, pp. 24-25).

Lo humano emerge, entonces, como lo indispensable, si no se quiere perder el horizonte de lo esencial. Martha Nussbaum lo referencia en sus textos permanentemente porque, como Sócrates, busca lo bueno, lo eterno y lo bello del ser humano: "[...] los valores socráticos se emplean para formar un tipo de ciudadano en particular: un ser activo, crítico, curiosos y capaz de oponer resistencia a la autoridad y a la presión de sus pares" (Nussbaum, 2010, p. 105).

Es con relación a esta demanda de formación de un ciudadano crítico que emerge la escuela como el lugar privilegiado para su despliegue. El desarrollo de las culturas, la construcción de una vida ética reflexiva y crítica, la vivencia moral en torno a la persona, el devenir global de las sociedad, conllevan a la necesidad de formación y praxis de una ciudadanía abierta y constructiva centrada en el reconocimiento del otro y en la promoción de una vida digna integral, como caminos especiales para superar cualquier perspectiva hegemónica de dominio y discriminación. Al respecto señala Nussbaum en Sin fines de Lucro (2010):

¿Qué es lo que nos enseña este análisis en la búsqueda de lo que puede y debe hacer la escuela para generar ciudadanos de la democracia?

--Desarrollar la capacidad del alumno de ver el mundo desde la perspectiva del otro [...] inculcar [...] que ser débil no es vergonzoso y que necesitar a los demás no es indigno de un hombre [...] desarrollar la capacidad de sentir un interés genuino por los demás [...] La escuela puede socavar la tendencia a alejarse de las minorías en un acto de repugnancia, por considerarlas "inferiores" o "contaminantes"

(Nussbaum, 2010, pp. 73-74). 


\section{El rol de género como categoría fundante del desarrollo humano}

El enfoque de las capacidades desarrollado por Nussbaum tiene como horizonte el desarrollo humano de la sociedad. En efecto, Nussbaum cuestiona cualquier perspectiva y sistema político y económico que centran su interés o atienden a la consideración de que el progreso social tiene como fuente el desarrollo económico, propiamente, mediante el aumento del producto interno bruto (2010, p. 34), al margen de otros aspectos de la vida humana. De ahí que este enfoque confronta inicialmente lo económico con relación a valorar la existencia del ser humano, cuestiona el planteamiento de que la producción económica esté por encima o ajena al desarrollo de la dignidad humana.

En este sentido, si el horizonte es la constitución de la dignidad humana, ésta imprime un carácter universalista integrador de cualquier forma de elección de la vida humana "independientemente de la raza, el género o la religión [...]" (Nussbaum, 2010, p. 37). De ahí que todo Estado, toda Constitución, deben preservar la igualdad de sus ciudadanos en todos los ámbitos en los que se desarrollen independientemente de las formas de vida o elecciones particulares de vivencia de género. Desde el enfoque humanista de Nussbaum se precisa la dignidad por encima de dichas elecciones de vida, esto es, por ejemplo, ser varón o mujer, no son formas constituidas o establecidas de lo humano, sino, más bien, puntos de partida de elección y vivencia. El rol de género, entonces, constituye un asunto que debe ser no sólo reconocido por el Estado o la Constitución, sino ante todo, un aspecto particular del ejercicio de la libertad y del desarrollo de la persona que se debe respetar, específicamente, mediante el pleno ejercicio de la inclusión social, más aun, como una práctica que supere las "luchas por la integración y la igualdad, como los debates sobre la inmigración, las polémicas sobre la aceptación de las minorías étnicas, raciales y religiosas, las controversias sobre la igualdad de género y la orientación sexual [...]" (Nussbaum, 2010, p. 54).

Se constituye así un llamado a la reivindicación de la identidad, de los derechos de la población minoritaria de diversa orientación sexual, que especialmente aguarda una perspectiva crítica que pone el acento en la constitución de la persona, de su identidad y de sus derechos, de manera independiente a la orientación sexual que por sí misma constituya. Esto es, un elemento de la dignidad es el respeto de la individualidad, a la intimidad propia del ser humano. Esto precisa la necesidad de una educación atenta al conocimiento de los grupos diversos existentes en la sociedad, encaminada a una comprensión integral del entorno cultural de una sociedad, a la búsqueda de la equidad de género, a la tolerancia, y en general, a la praxis de una ciudadanía inclusiva y de cooperación. En este sentido, insiste Nussbaum: "[...] se requiere el conocimiento sobre los varios subgrupos étnicos, nacionales, religiosos y de género que conforman la propia nación, y sobre los logros, las luchas y los aportes de esos subgrupos, pero también sobre las tradiciones y las naciones ajenas” (2010, p. 115). De hecho, 
según Nussbaum, este educación ha de dar lugar una perspectiva comprehensiva e incluyente de lo andrógino, esto es, de aquellas manifestaciones externas en una persona que no se corresponden con su naturaleza sexual, pero que, en todo caso, constituyen la dinámica de su personalidad. De su experiencia como investigadora en la India, relata en "Sin fines de lucro":

Los roles que ocupaban los hombres en la danza bajo el auspicio de Tagore también representaban un desafío para ellos, y el mismo gozaba de gran prestigio como bailarín y coreógrafo, sobre todo por sus movimientos sinuosos y andróginos. En las obras coreográficas, era muy frecuente que apareciera una temática explícita dirigida a cuestiones de género [...] (2010, p. 143).

Johann Gottfried Herder escribió en 1792 que los buenos ciudadanos debian aprender que la virilidad no requería una agresividad belicosa contra las otras naciones [...], sostenía que los hombres europeos debian imitar el hábito de colocarse prendas femeninas para deliberar sobre la guerra y la paz (2010, p. 150).

Estas citas denota como fundamental para la democracia la praxis de una identidad inclusiva del hombre y la mujer en el rol sociocultural que cada uno tiene, o mejor, la vivencia incluyente de todas aquellas imágenes de género que se van tejiendo en la cultura, que son despliegue de formas diversas de relacionarse la persona y que se constituyen en fundamento de una democracia incluyente y de un auténtico desarrollo humano. Precisa Nussbaum:

Hemos mencionada algunas cuestiones relativas a las imágenes de género, y tal vez no exista condición más fundamental para la salud de la democracia que poseer una imagen sana de lo que es un hombre verdadero y cómo se relaciona con las mujeres y con los otros hombres (Nussbaum, 2010, pp. 149 -150).

La crítica reflexiva a aquellas prácticas de discriminación cultural a dichas formas diversas de manifestación del género, ha posibilitado el despliegue, el menos en parte, de una perspectiva integradora de lo humano, pero requiere de un fuerte despliegue de prácticas educativas centradas, por ejemplo, en los siguientes aspectos: las diferencias y roles establecidos socialmente para cada uno de los géneros, el currículo y las prácticas pedagógicas, las orientaciones vocacionales, las relaciones humanas, los imaginarios presentes en la interacción social y la protección de los derechos humanos, entre otros.

Un paso importante ha sido el hecho mismo de que durante los últimos años se han generado diversos movimientos sociales en torno a las comunidades LGBTI alrededor del mundo, incluyendo Colombia. Estos procesos y manifestaciones han despertado el interés de diferentes sectores económicos y culturales, lo que a su vez, ha hecho evidente el número, cada vez más alto, de personas pertenecientes a dicha población, por ello, se han desarrollado investigaciones abordando como objeto de estudio la corporeidad y la subjetividad. Tal es el 
caso de Betancourt (2012) que hace una re-lectura del género desvinculando su relación existente en la corporalidad y enfocándose hacia las prácticas de sujeción y la construcción de subjetividades; o la investigación realizada por Herrera (2012) que aborda la comunicación y el interaccionismo simbólico, vistos desde lo masculino y lo femenino, las relaciones cuerpo y espacio; Dubois (2010) quien pone de manifiesto nuevas formas de ver la sexualidad de esta comunidad y su desarrollo comunitario.

A nivel político y cultural se han desarrollado investigaciones referidas a los derechos que tienen las personas de dichas comunidades como miembros activos de la sociedad, así como el interés por su ser identidad como personas. Es el caso de Martínez (2013) donde se analiza el marco legal, los programas de educación sexual y de construcción de ciudadanía enmarcados por el Ministerio de Educación Nacional; Mancipe (2011) donde se plantea y analiza la subjetividad política, la discriminación por la diversidad sexual y la búsqueda de la protección de los derechos; asimismo, el trabajo ya mencionado trabajo de Herrera (2012) que presenta la problemática de los jóvenes escolares con respecto al género y su expresión en la escuela.

Ahora bien, estas investigaciones ponen de manifiesto el interés social que se ha venido constituyendo con relación a la búsqueda de una sociedad incluyente respecto de aquellas formas diversas de constitución de género, aunque se denota que abordaron los aspectos mencionados en forma separada, la mayoría de ellas en relación a un grupo poblacional específico. Por tanto, para esta investigación resulta necesario e importante aproximar una perspectiva de análisis en forma integrada y alrededor de planteamientos teóricos contemporáneos, como el desarrollado por Martha Nussbaum, de modo que se constituya un aporte teórico a la antropología educativa y en respuesta a las necesidades de reconocimiento, dignificación y despliegue de las capacidades humanas como camino para la constitución de la identidad personal y su relación recíproca, respetuosa y acogedora en un contexto, como lo señala Hamann:

Las capacidades de interaccionar con el mundo, de actuar, de realizar cosas (entre ellas cabe mencionar el observar, el coger algo, el husmear. El andar, el jugar, el hablar, el pensar, la acción productiva [...]). El niño necesita tales capacidades a fin de poder dominar las situaciones históricas de su vida, realizar sus interacciones individuales, apropiarse de la cultura y fomentar la comprensión de sí mismo (1992, p. 23).

Se trata de la promoción despliegue de capacidades puestas al alcance de los estudiantes, en sus formas de vida significativas y cotidianas, que fortalezcan las relaciones personales entre todos los miembros de la comunidad, la interiorización de valores humanos, de perspectivas éticas incluyentes, que reduzcan las acciones de discriminación y posibiliten el desarrollo de ciudadanos conscientes de las responsabilidades cívicas y democráticas que tienen con el país y con el mundo. 


\section{Metodología.}

Para ampliar el espectro de comprensión respecto al género como categoría fundante de la identidad personal, en esta investigación, mediante un ejercicio etnográfico, se recogió información de parte de docentes, estudiantes y egresados de varias instituciones educativas escogidas de forma aleatoria, con el fin de consolidar insumos contextuales que permitan identificar la comprensión que se ha configurado en el ámbito escolar respecto de la categoría del rol de género, y confrontarla con el enfoque humanista desarrollado por Nussbaum. Mediante un análisis crítico, se pueden indicar, entre otros, los siguientes aspectos.

Primero, aunque se entrevé una búsqueda de equidad entre el hombre y la mujer, es una constante en la mayoría de docentes con respecto al tema del género una radical diferencia entre lo que se entiende como hombre y como mujer, lo cual deviene y se manifiesta en muchos casos como machismo y en la comprensión cultural de roles específicos para cada uno. En todo caso, una minoría manifiesta una aceptación de nuevas identidades, (homosexuales, heterosexuales, bisexuales, entre otras) bajo una comprensión del rol de género desde los valores de la inclusión, la tolerancia, la libre expresión, el diálogo y el respeto. Tal comprensión ha buscado caminos en donde se les brinde apoyo para fundamentar la autoconfianza y la autoestima, ya que se enfrentan a una sociedad multicultural y excluyente. Se destacan, asimismo, aquellos que minimizan la situación, que no dan la relevancia necesaria al tema, lo pretenden ignorar $u$ ocultar y, por lo tanto, se configura y alimenta aquella perspectiva que no da relevancia al tema de los derechos de las minorías.

Segundo, en cuanto a los jóvenes egresados, puede indicarse que se entrecruza una idea centrada en el machismo, como consecuencia del desarrollo histórico de la cultura y de los estereotipos que respecto de la mujer y del hombre se han configurado. Asunto que se hace manifiesto en la inferioridad de la mujer, en una perspectiva según la cual el papel de la mujer ha sido relegado a lo débil y a lo maternal. De hecho, se destaca una fuerte influencia de la moral religiosa, aquella que apoya la idea de exclusión diferenciadora o la brecha entre lo que puede significar lo masculino y lo femenino. Cabe indicar que aquellos jóvenes que reconocen la construcción de su identidad personal desde otras inclinaciones sexuales reclaman ante todo un trato igualitario, y de hecho, la necesidad de debatir o constituir este enfoque del género en un asunto de la cotidianidad existencial, esto es, un asunto público.

Tercero, con relación a los estudiantes, el tema de género se plantea en dos perspectivas. Por una parte, un primer planteamiento precisa que la mayoría de los estudiantes da por sentado que hay diversidad de roles de género los cuales se deben respetar, indicando que no se deben excluir ni estigmatizar. En esta perspectiva, se propende por la equidad, el reconocimiento social y 
respeto por sus sentimientos, formas de pensar y comportamientos, dado que, indican los estudiantes, tiene las capacidades intelectuales y físicas como cualquier otra persona. Esto constituye para los estudiantes el elemento base para la lucha por la igualdad de derechos entre el hombre y la mujer en todos los campos, ya sea laboral, político, religioso, cultural, entre otros. Aguarda, además, una perspectiva de reivindicación de la mujer en la sociedad, esto es, no como ser pasivo sino activa y determinante de la construcción de la cultura y la sociedad. Por otra parte, se evidencia el despliegue de un discurso que puede caracterizarse como tradicional, en el sentido en que el género se entiende como la naturalización de una identidad propia tanto del hombre como de la mujer que por generaciones se ha tenido como la base de una sociedad, lo que de hecho, se ha configurado como un marco natural y jurídico aceptado.

Con todo, la emergencia social y política de grupos minoritarios, como es la población LGBTI, deviene como un elemento sustantivo en la medida en que ha posibilitado la reflexión y el debate político alrededor de lo que implica el rol de género, a la vez que se han configurado voces y acciones de aceptación y convivencia, que buscan ante todo la praxis de los derechos de toda una sociedad, al atender a las demandas no reconocidas hasta entonces por la misma. Cabe señalar que esto ha confluido de forma significativa, además, y así lo destacan tanto docentes, estudiantes y egresados, hacia la reestructuración de todo el andamiaje jurídico de la sociedad global.

En este contexto ¿Cuál es el lugar de la educación con relación a lo planteado? Martha Nussbaum plantea en "Sin ánimo de lucro" (2010), que una sociedad que se construye en y para la diversidad se enriquece y genera nuevas posibilidades para el desarrollo de la misma:

Mann afirmaba que ninguna democracia podia perdurar salvo que sus ciudadanos recibieran una buena educación y adoptaran una postura activa. En lo que respecta a la integración, sostenía una posición revolucionaria, pues insistía en la educación igualitaria para todos los niños, independientemente del sexo o raza [...] (Nussbaum, 2010, p. 94).

Esto demanda para la escuela promover una revolución crítica no sólo de orden conceptual sino axiológico y cultural, en la medida en que posibilite el desarrollo de un lenguaje de igualdad, fortalezca los valores de la tolerancia y facilite el ejercicio de una ciudadanía inclusiva. La escuela deviene como el espacio privilegiado para la praxis de una ciudadanía centrada en el desarrollo y la valoración de lo humano, o lo que es, en la persona. El trabajo realizado con los docentes, estudiantes y egresados permite señalar que, de manera concreta, se hace necesario plantear y desarrollar en y desde la escuela tres aspectos relevantes: primero, trabajar sobre el buen trato, es decir, el reconocimiento y aceptación del otro como par; segundo, fortalecer el diálogo permanente con los padres de familia, lo cual demanda la necesidad de vincular directamente la familia con el contexto escolar; y tercero, apoyar y visibilizar el tema del rol de 
género en el aula, esto es, el desarrollo de prácticas pedagógicas en las que se constituya como el eje temático y horizonte de reflexión y aprendizaje.

Desde el enfoque de las capacidades desarrollado por Nussbaum se entrevé la necesidad de promover en la escuela un pensamiento crítico alrededor de la inclusión y desde los valores de la equidad, la tolerancia y el trato igualitario. Desde este enfoque el rol de género es la oportunidad para la valoración de la vivencia de toda identidad personal frente al contexto cultural y social globalizado, especialmente de aquella población minoritaria, de modo que se priorice el valor de la persona como sujeto de capacidades que hace parte de una sociedad incluyente y democrática. La educación es así la base constitutiva de una ciudadanía igualitaria, incluyente y democrática, en la medida en que promueve el diálogo permanente y la apertura hacia toda forma de construcción de identidad personal, por cuanto, además, la ciudadanía tiene como base el reconocimiento desinteresado del otro, o lo que es, la comunión inmediata y responsable con el otro (Gevaert, 1981, p. 31).

A modo de conclusión, se puede indicar que una educación humanista se configura así como un elemento constitutivo de la ciudadanía, en cuanto dinamiza el valor de ser persona frente al despliegue de perspectivas utilitaristas e individualistas. En tal sentido, si atiende de forma crítica al rol del género caracteriza el encuentro desinteresado e incluyente hacia los otros en sentido amplio, es decir, más allá de lo que comúnmente es aceptado por cada persona en particular. Como se indicó atrás, la puesta en escena reflexiva y política del rol de género a la vez que llama la atención sobre los grupos minoritarios, demanda una comprensión humana de la persona, independientemente de las formas de identidad personal que se asuman. 


\section{Referencias bibliográficas}

Betancourt, G. A. 2012. Imitar y castigar: La ortopedia social en los cuerpos del hombre y el arte de la normalización (Tesis de maestría). Bogotá: Universidad Nacional de Colombia.

Dubois, M. 2010. Los grupos LGBT: entre la subjetivación política y el desarrollo comunitario. (Tesis de doctorado). Bogotá: Universidad Pedagógica Nacional.

Gevaert, J. 1981. El Problema del Hombre, Introducción a la antropología filosófica. Salamanca: Sígueme

Hamann, B. 1992. Antropología pedagógica. Introducción a sus teorías, modelos y estructuras. Madrid: Vicens Vives.

Herrera, J. 2012. Disolución y homogenización del género lecturas de lo masculino y lo femenino en jóvenes adolescentes (Tesis de maestría). Bogotá: Universidad Distrital.

Mancipe, J. C. 2011. Construcción de las subjetividades politicas en jóvenes del movimiento LGBT de la localidad de chapinero (Tesis de doctorado). Bogotá: Universidad Pedagógica Nacional; Cinde.

Martínez, Y. 2013. Más allá del género y sus derechos hacía una subjetividad política formada desde la indeterminación de la identidad sexual (Tesis de maestría) Bogotá: Universidad Distrital de Colombia.

Nussbaum, M. 2005. El cultivo de la humanidad. Una defensa clásica de la reforma en la educación liberal. Barcelona: Paidós.

Nussbaum, M. 2010. Sin fines de lucro: porque la democracia necesita de las humanidades. Madrid: Katz Editores.

Nussbaum, M. 2012. Crear capacidades. Propuesta para el desarrollo humano. Barcelona: Paidós. 